\title{
SPATIAL VARIABILITY OF TURBULENT FLUXES IN THE ROUGHNESS SUBLAYER OF AN EVEN-AGED PINE FOREST
}

\author{
GABRIEL KATUL ${ }^{1, *}$, CHENG-I HSIEH ${ }^{1}$, DAVID BOWLING ${ }^{2}$, KENNETH CLARK $^{3}$, \\ NARASINHA SHURPALI ${ }^{4}$, ANDREW TURNIPSEED $^{2}$, JOHN ALBERTSON $^{5}$, \\ KEVIN TU $^{6}$, DAVE HOLLINGER ${ }^{6}$, BOB EVANS ${ }^{6}$, BRIAN OFFERLE ${ }^{4}$, DEAN \\ ANDERSON $^{7}$, DAVID ELLSWORTH ${ }^{1,8}$, CHRIS VOGEL $^{9}$ and RAM OREN ${ }^{1}$ \\ ${ }^{1}$ School of the Environment, Duke University, Durham, NC 27708-0328, U.S.A.; ${ }^{2}$ Environmental, \\ Population, and Organismic Biology, University of Colorado, Bolder, CO 80309, U.S.A.; ${ }^{3}$ School of \\ Forest Resources and Conservation, University of Florida, Gainesville, FL 32611, U.S.A.; \\ ${ }^{4}$ Department of Geography, Indiana University, Bloomington, IN 47405, U.S.A.; ${ }^{5}$ Department of \\ Environmental Sciences, University of Virginia, Charlottesville, VA 22903, U.S.A.; ${ }^{6}$ United States \\ Department of Agriculture Forest Service, 271 Mast Rd., Durham, NH 03824, U.S.A.; ${ }^{7}$ United \\ States Geological Survey, M.S.413, Federal Center, Denver, CO 80225, U.S.A.; ${ }^{8}$ Brookhaven \\ National Laboratory, Upton, Long Island, NY 11973, U.S.A.; ${ }^{9}$ University of Michigan Biological \\ Station, 9008 Biological Rd, Pellston, MI 49769, U.S.A.; * Current address: Environment and \\ Ecology, School of Humanities and Social Sciences, National Taiwan University of Science and \\ Technology, Taipei 10660, Taiwan
}

(Received in final form 7 April 1999)

\begin{abstract}
The spatial variability of turbulent flow statistics in the roughness sublayer (RSL) of a uniform even-aged $14 \mathrm{~m}(=h)$ tall loblolly pine forest was investigated experimentally. Using seven existing walkup towers at this stand, high frequency velocity, temperature, water vapour and carbon dioxide concentrations were measured at $15.5 \mathrm{~m}$ above the ground surface from October 6 to 10 in 1997. These seven towers were separated by at least $100 \mathrm{~m}$ from each other. The objective of this study was to examine whether single tower turbulence statistics measurements represent the flow properties of RSL turbulence above a uniform even-aged managed loblolly pine forest as a best-case scenario for natural forested ecosystems. From the intensive space-time series measurements, it was demonstrated that standard deviations of longitudinal and vertical velocities $\left(\sigma_{u}, \sigma_{w}\right)$ and temperature $\left(\sigma_{T}\right)$ are more planar homogeneous than their vertical flux of momentum $\left(u_{*}^{2}\right)$ and sensible heat $(H)$ counterparts. Also, the measured $H$ is more horizontally homogeneous when compared to fluxes of other scalar entities such as $\mathrm{CO}_{2}$ and water vapour. While the spatial variability in fluxes was significant $(>15 \%)$, this unique data set confirmed that single tower measurements represent the 'canonical' structure of single-point RSL turbulence statistics, especially flux-variance relationships. Implications to extending the 'moving-equilibrium' hypothesis for RSL flows are discussed. The spatial variability in all RSL flow variables was not constant in time and varied strongly with spatially averaged friction velocity $u_{*}$, especially when $u_{*}$ was small. It is shown that flow properties derived from two-point temporal statistics such as correlation functions are more sensitive to local variability in leaf area density when compared to single point flow statistics. Specifically, that the local relationship between the reciprocal of the vertical velocity integral time scale $\left(I_{w}\right)$ and the arrival frequency of organized structures $(\bar{u} / h)$ predicted from a mixing-layer theory exhibited dependence on the local leaf area index. The broader implications of these findings to the measurement and modelling of RSL flows are also discussed.
\end{abstract}

Keywords: Canopy turbulence, Moving equilibrium hypothesis, Planar homogeneity, Roughness sublayer, Spatial variability, Turbulent fluxes. 


\section{Introduction}

Long-term monitoring of carbon dioxide $\left(\mathrm{CO}_{2}\right)$ and water vapour fluxes above a wide range of ecosystems has recently received much attention worldwide with the establishment of measurement networks in Europe and North America (Kaiser, 1998). There is particular interest in monitoring fluxes above tall forested ecosystems because of the magnitude of their mass and energy exchange with the atmosphere (Wofsy et al., 1993). Above tall forests, long-term carbon dioxide $\left(F_{c}\right)$, water vapour (LE), and sensible heat fluxes $(\mathrm{H})$ are commonly measured using eddy covariance methods within the so-called roughness sublayer (hereafter referred to as RSL). The RSL is loosely defined as that layer within the atmospheric boundary layer (ABL) that is dynamically influenced by length scales associated with the roughness elements and is situated below the inertial sublayer (in which logarithmic profiles exist for mean velocity and other mean scalar concentration entities for neutral conditions). The RSL typically ranges from the mean canopy height $h$ to $2-5 h$ (Raupach and Thom, 1981). The structure of turbulence within the RSL is complicated by its neighbourhood to quasi-random distribution of air spaces embedded in three-dimensional arrays of sources and sinks of momentum and scalar entities (Kaimal and Finnigan, 1994). Despite this complexity, the statistical description of turbulence within the RSL is commonly assumed one-dimensional, varying only in the vertical $(z)$ direction (Kondo and Akashi, 1976; Wilson and Shaw, 1977; Lewellen et al., 1980; Albini, 1981; Moritz, 1989; Raupach and Thom, 1981; Raupach and Shaw, 1982; Raupach, 1988; Raupach et al., 1991, 1996; Wilson, 1988, 1989; Amiro and Davis, 1988; Amiro, 1990; Baldocchi and Meyers, 1988).

Theoretical justification for a one-dimensional flow approximation is attributed to horizontal averaging the time-averaged equations of motion for momentum and scalar conservation (Wilson and Shaw, 1977; Raupach and Shaw, 1982). Hence, flow statistics modelled from such equations represent horizontally averaged quantities. Nonetheless, comparisons between model predictions and field measurements are typically based on single tower experiments (Meyers and Paw U, 1986; Wilson, 1988, 1989; Raupach, 1988; Katul et al., 1997a; Katul and Albertson, 1998; Katul and Chang, 1999) and not horizontally averaged flow statistics. Whether single-point measurements above the canopy represent horizontally averaged flow statistics or the 'canonical' dynamics of turbulent transport within the RSL of tall forests has not been explored experimentally. This question also has significance for understanding the extent to which a single eddy-covariance flux monitoring system above forested canopies can be extrapolated to the scale of the forest stand.

The objective of this study is to examine whether single-tower turbulence statistics measurements represent the flow properties of RSL turbulence above a uniform, even-aged forest as a best-case scenario for natural forested ecosystems, many of which are not even-aged and are often populated by multiple 
dominant species. Specifically, the spatial variability of turbulence statistics, the spatial homogeneity of scaled similarity relations, and the influence of local canopy morphology on characteristic length/time scales are analyzed. These objectives address whether single-tower measurements represent horizontally averaged flow statistics, canonical similarity structure of turbulent transport, and the influence of canopy morphology on basic characteristic length and time scales governing vertical transport of mass, heat, and momentum. While few sites have an appropriate infrastructure for conducting an experiment to investigate these issues, the seven towers (height $=15.5 \mathrm{~m})$ within a $1000-\mathrm{m}$ by $305-\mathrm{m}$ pine stand $(h=14 \mathrm{~m})$ at Duke Forest offered such an opportunity. The towers were constructed for an elevated $\mathrm{CO}_{2}$ experiment and are separated from each other by at least $100-\mathrm{m}$ horizontal distance. For a sequence of four days in October of 1997, high frequency measurements of velocity, temperature, water vapour and carbon dioxide concentrations were simultaneously collected at the seven towers and spatial variability in turbulent statistics was analyzed.

Before proceeding with the analysis, notations are first introduced. The streamwise, lateral and vertical coordinates are $x, y, z$, the instantaneous velocity components along these three directions are $u, v$, and $w$, respectively, the instantaneous temperature, water vapour concentration, and carbon dioxide concentration are $T, q$, and $c$ respectively, overbar represents time averaging, $\langle$.$\rangle represents planar$ averaging, and single primes denote departures from time averaging with $\overline{u^{\prime}}=\overline{v^{\prime}}=$ $\overline{w^{\prime}}=\overline{T^{\prime}}=\overline{q^{\prime}}=\overline{c^{\prime}}=0$, double primes denote departures from planar averaging, and $u_{*}\left(=-{\overline{u^{\prime} w^{\prime}}}^{1 / 2}\right)$ is the local friction velocity above the canopy. Since we focus on measurements just above the canopy, the terms canopy sublayer (CSL) and roughness sublayers are used interchangeably. Formally, the major distinction between these two layers is that the roughness sublayer is defined just above roughness elements (usually defined for $z / h=1$ to $2-5$ ) while the canopy sublayer includes the roughness sublayer as well as the air volume inside vegetation (usually defined for $z / h=0 \sim 2-5$ ). Other definitions decompose the CSL into multiple layers depending on the processes that balance the production of turbulence (Finnigan, 1985).

\section{Experiment}

\subsection{THE SITE}

An experiment was conducted from October 6-10, 1997 at the Blackwood Division of the Duke Forest near Durham, North Carolina $\left(35^{\circ} 98^{\prime} \mathrm{N}, 79^{\circ} 8^{\prime} \mathrm{W}\right.$, elevation of $163 \mathrm{~m}$ ). The site is a uniformly-aged managed loblolly pine forest that extends at least $1000 \mathrm{~m}$ in the north-south direction and $300 \mathrm{~m}$ to $600 \mathrm{~m}$ in the east-west direction. The stand, originally grown from seedlings planted at $2.4 \mathrm{~m} \times 2.4 \mathrm{~m}$ spacing in 1983 following clear cutting and burning, is approximately $14 \mathrm{~m}$ tall. 
Given the stand uniformity and the tree-to-tree spacing in relation to the canopy height, the stand can be classified as extensive (i.e., the tree-to-tree spacing is an order of magnitude smaller than the mean tree height). Six central walkup towers at the Free Air $\mathrm{CO}_{2}$ Enrichment (FACE) Rings (see Ellsworth et al., 1995 for description), which are part of an on-going Forest-Atmosphere Carbon Transfer and Storage (FACTS) experiment, were used when the $\mathrm{CO}_{2}$ enrichment was shut down for routine maintenance and repairs. Three of the six towers were in Rings continuously exposed to 560 ppm elevated atmospheric $\mathrm{CO}_{2}$ during 1997, although there were no significant long-term effects of elevated $\mathrm{CO}_{2}$ on leaf area or physiological properties of the foliage other than photosynthetic enhancement as of the time of this study (Ellsworth, 1999).

The walkup-tower and the mean canopy heights are $15.5 \mathrm{~m}$ and $14.0 \mathrm{~m}$ $( \pm 0.5 \mathrm{~m})$ respectively. A seventh central walkup tower (tower height $=20.6 \mathrm{~m})$ for a prototype FACE Ring is also present in the same stand (see Katul et al., 1996a, 1997a,b). The seven FACE Rings and local topographic variations are shown in Figure 1. From Figure 1, it is important to note that the separation distance between Rings is at least $100 \mathrm{~m}$, and much of the local topographic variations are small ( $<5 \%$ slopes) so that their influence on turbulent transport can be neglected (Kaimal and Finngan, 1994).

\subsection{LEAF AREA DENSITY VARIATIONS}

The leaf area density was measured one week prior to the experiment near each measurement tower using a LICOR 2000 canopy analyzer. Measurements were made for a $180^{\circ}$ view masking the central tower for two azimuthal directions from the tower. Since the predominant wind directions were northerly, the northern azimuth readings were used throughout in this study. The conversion of these measurements to leaf area density is discussed in Katul et al. (1997a). The leaf area index (LAI) at these seven locations varied from 2.65-4.56 $\mathrm{m}^{2} \mathrm{~m}^{-2}$ (coefficient of variation $=18 \%$ ). The measured leaf area density profiles for each tower site are shown in Figure 2. For clarity, the cumulative leaf area density is displayed such that at the canopy top the cumulative leaf area density of the stand becomes identical to LAI. Implications of such LAI variations on turbulent statistics and characteristic length and time scales is discussed in Section 3.3.

\subsection{INSTRUMENTATION SETUP AND LOGGING}

Seven research groups participated in the experiment with each group measuring turbulent fluxes at the top of one of the FACE towers (see Figure 1 for tower locations in the $x-y$ plane). Each participating group assembled their own eddy covariance system on October 4 and 5 (see Table I) and measurements from all Rings (except Ring 2) commenced midday of October 6. The predominant wind direction was from north to south. The measurements from Ring 2 were intermittent and were primarily used in cross-comparisons of instruments. The sampling 


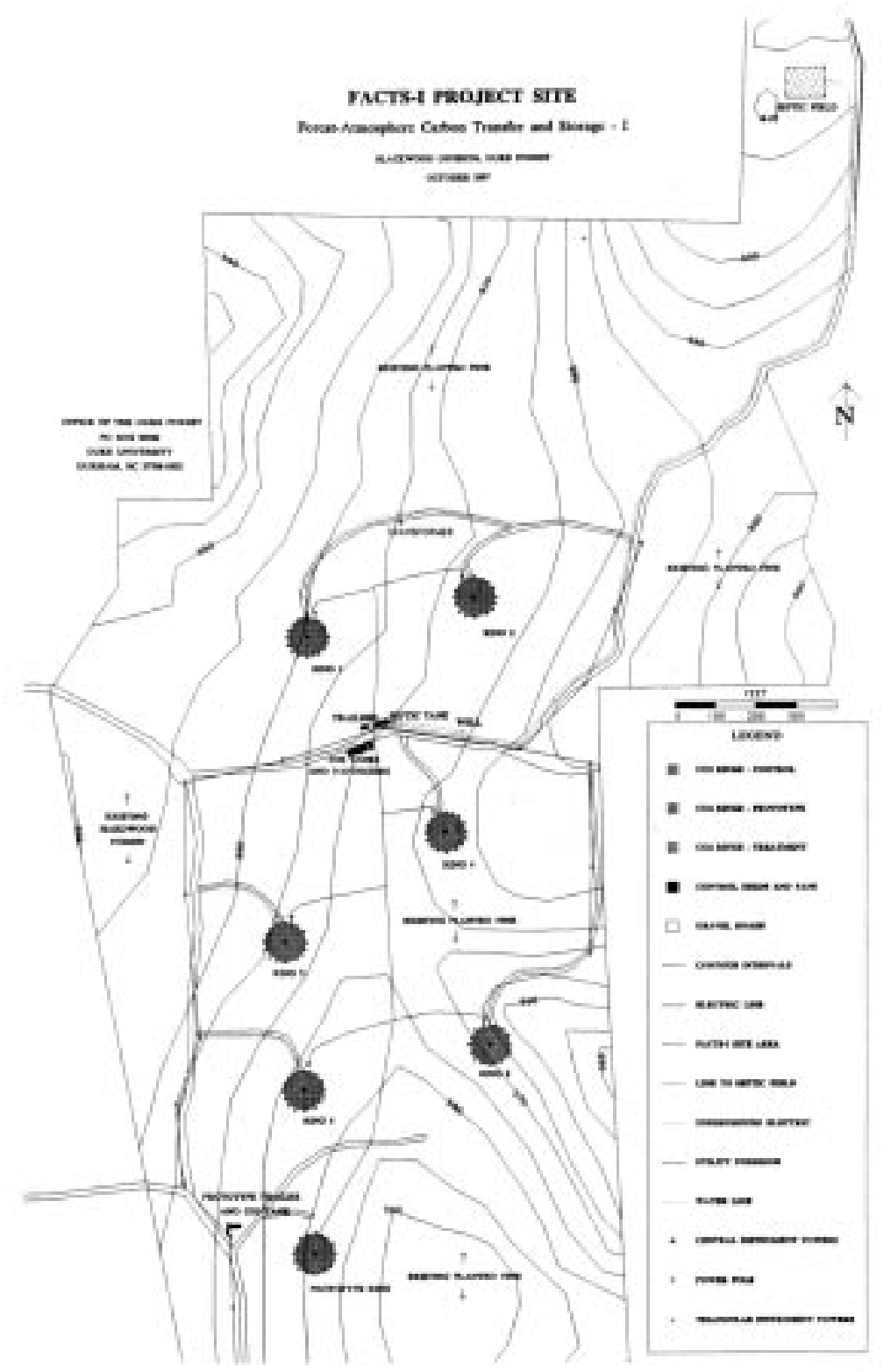

Figure 1. Site description, topographic variation, and relative Ring locations. For Rings 1 to 6 , the central walkup towers are $15.5 \mathrm{~m}$ tall. For the prototype ring (Ring 7), the walkup tower is $20.6 \mathrm{~m}$ tall. 


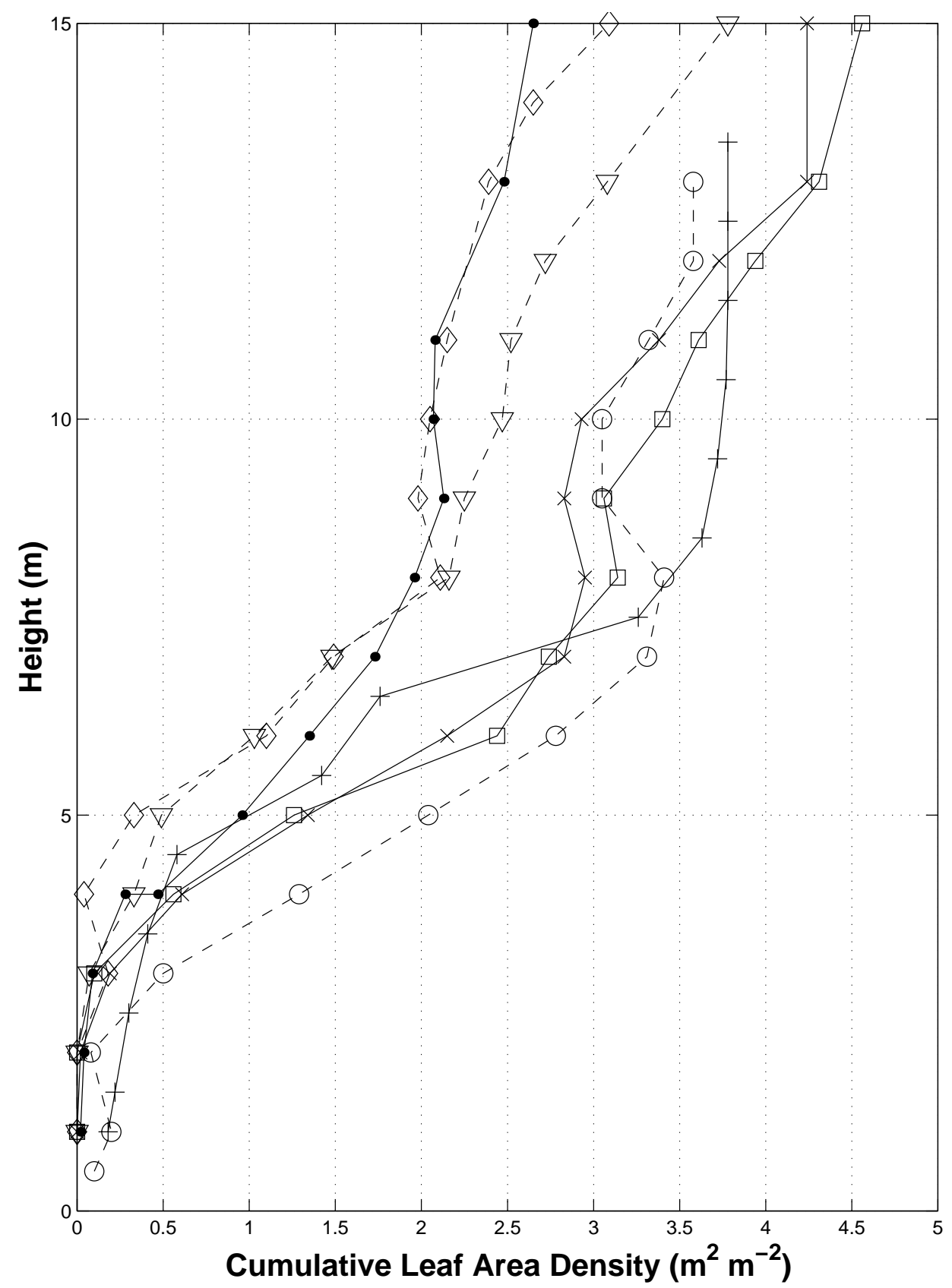

Figure 2. The variation of measured cumulative leaf area density with height (from the ground surface). The $x$-axis is displayed such that at the canopy-top the cumulative leaf area density is identical to LAI. The symbols are as follows: dot for Ring 1, triangle for Ring 2, square for Ring 3, diamond for Ring 4, $x$ for Ring 5, circle for Ring 6, and plus for Ring 7. 
frequencies for these systems ranged from 5 to $10 \mathrm{~Hz}$ and the averaging period $\left(T_{p}\right)$ was $30 \mathrm{~min}$ for all Rings. All raw signals from the seven logging devices were stored for consistent post-processing; clocks from all logging devices were synchronized just prior to the experiment on October 5.

\subsection{VELOCITY AND AIR TEMPERATURE MEASUREMENTS}

The three velocity components and air temperature fluctuations at each central tower were measured by sonic anemometers positioned at $15.5 \mathrm{~m}$ (tower top) for Rings 1 to 6 , and at $18 \mathrm{~m}$ for Ring 7. The eddy-covariance system configurations of different groups employed different sonic anemometers. A Campbell Scientific triaxial anemometer with a $14.1 \mathrm{~cm}$-path length (hereafter referred to as CSAT3) was used in Rings 1, 2, 5, and 7. An Applied Technology Inc. triaxial sonic anemometer with a 15-cm path length (hereafter referred to as ATI) was used in Rings 2, 3, and 6. A Solent Gill anemometer with a $14.9-\mathrm{cm}$ path length (hereafter referred to as GILL) was used in Ring 4. In Ring 2, simultaneous ATI and CSAT3 velocity and temperature measurements were available for only 1.7 days. Given differences in sonic designs, we performed two cross-comparison experiments to assess how much of the observed differences in turbulent statistics can be attributed to instrumentation differences. The first comparison was between an ATI co-located with a CSAT3 at Ring 2 during October 6-8. The second was a comparison between the two most different eddy-covariance system configurations (used in Rings 1 and 4) performed on October 12 and 13 at Ring 1. In the latter experiment, the eddy-covariance system was moved from Ring 4 to Ring 1 and co-located with the existing system in Ring 1 . The latter experiment included comparisons between the CSAT3 and the GILL as well as $\mathrm{CO}_{2}$ and water vapour fluxes (described next). A summary of instrumentation used at each tower is presented in Table I.

\subsection{CARBON DIOXIDE AND WATER VAPOUR CONCENTRATION MEASUREMENTS}

The carbon dioxide and water vapour concentration fluctuations were measured using a LICOR 6262 infrared gas analyzer (except in Ring 4 in which a LICOR 6250 was used in conjunction with a Campbell Scientific Krypton Hygrometer). Description of flow rates and tubing diameters are presented in Table I. Additionally, water vapour concentration fluctuation measurements by a Krypton hygrometer were performed in conjunction with the LICOR 6262 measurements at Rings 1 and 7. A direct comparison between the Krypton hygrometer and LICOR 6262 measurements of water vapour concentration fluctuations is also presented in Appendix A. The raw data processing for all systems was identical and was performed using the procedures described in Katul et al. (1997a,b) with scalar covariance computed after maximizing the cross correlation between vertical velocity fluctuations and scalar concentration fluctuations for each 30-min run. The processed velocity statistics and scalar flux time series for each Ring are shown in Figures 3a and 3b, 
TABLE I

Measuring instruments at the seven towers: CSAT3 = Campbell Scientific Instruments (CSI) sonic anemometer, ATI = Applied Technology Inc, KH2O = CSI Krypton hygrometer, LICOR $=$ LICOR infrared gas analyzer, GILL $=$ Gill sonic anemometer.

\begin{tabular}{|c|c|c|c|}
\hline Ring \# & Investigator & Sonic type & Scalar measurement \\
\hline 1 & G. Katul/C.I. Hsieh & CSAT3 & $\begin{array}{l}\text { LICOR 6262, KH2O } \\
\text { Flow Rate }=7 \mathrm{~L} \mathrm{~min}^{-1} \\
\text { Tube Length/Diameter }=3 \mathrm{~m} / 1 / 4^{\prime \prime} \\
\text { Sampling Frequency }=5 \mathrm{~Hz}\end{array}$ \\
\hline 2 & D. Anderson & ATI/CSAT3 & $\begin{array}{l}\text { LICOR } 6262 \\
\text { Flow Rate }=10 \mathrm{~L} \mathrm{~min}^{-1} \\
\text { Tube Length/Diameter }=5 \mathrm{~m} / 1 / 4^{\prime \prime} \\
\text { Sampling Frequency }=10 \mathrm{~Hz}\end{array}$ \\
\hline 3 & D. Bowling/A. Turnipseed & ATI & $\begin{array}{l}\text { LICOR } 6251, \mathrm{KH} 2 \mathrm{O} \\
\text { Flow Rate }=7 \mathrm{~L} \mathrm{~min}^{-1} \\
\text { Tube Length/Diameter }=5 \mathrm{~m} / 1 / 4^{\prime \prime} \\
\text { Sampling Frequency }=10 \mathrm{~Hz}\end{array}$ \\
\hline 4 & K. Clark & GILL & $\begin{array}{l}\text { LICOR } 6262 \\
\text { Flow Rate }=6 \mathrm{~L} \mathrm{~min}^{-1} \\
\text { Tube Length/Diameter }=20 \mathrm{~m} / 1 / 4^{\prime \prime} \\
\text { Sampling Frequency }=10 \mathrm{~Hz}\end{array}$ \\
\hline 5 & D. Hollinger/K. Tu & CSAT3 & $\begin{array}{l}\text { LICOR } 6262 \\
\text { Flow Rate }=5 \mathrm{~L} \mathrm{~min}^{-1} \\
\text { Tube Length/Diameter }=20 \mathrm{~m} / 3 / 16^{\prime \prime} \\
\text { Sampling Frequency }=5 \mathrm{~Hz}\end{array}$ \\
\hline 6 & N. Shurpali/B. Orff & ATI & $\begin{array}{l}\text { LICOR } 6262 \\
\text { Flow Rate }=30 \mathrm{~L} \mathrm{~min}^{-1} \\
\text { Tube Length/Diameter }=30 \mathrm{~m} / 1 / 2^{\prime \prime} \\
\text { Sampling Frequency }=10 \mathrm{~Hz}\end{array}$ \\
\hline 7 & J. D. Albertson & CSAT3 & $\begin{array}{l}\text { LICOR } 6262, \mathrm{KH} 2 \mathrm{O} \\
\text { Flow Rate }=6 \mathrm{~L} \mathrm{~min}^{-1} \\
\text { Tube Length/Diameter }=5 \mathrm{~m} / 1 / 8^{\prime \prime} \\
\text { Sampling Frequency }=10 \mathrm{~Hz}\end{array}$ \\
\hline
\end{tabular}

respectively. The spatial variability in these time series measurements is used to address the study objectives. 


\section{Results and Discussion}

To examine whether single-tower measurements of eddy-covariance turbulent fluxes represent basic statistical properties of RSL turbulence, this section is divided into three parts: spatial variability of turbulence statistics, homogeneity of similarity relations, and the role of local canopy morphology on the characteristic length/time scales. These three sections address whether single-tower measurements represent horizontally averaged flow statistics, canonical similarity structure of turbulent transport, and the influence of canopy morphology on characteristic length and time scales governing vertical motion.

\subsection{SPATIAL VARIABILITY OF FLOW STATISTICS}

The coefficient of variation $(C V(s))$ is commonly used as a non-dimensional statistic to quantify the spatial variability of a flow variable $(s)$ around its mean value for a given time period. The spatial coefficient of variation is defined as

$$
C V(s)=\frac{\sqrt{\left\langle\bar{s}^{\prime \prime 2}\right\rangle}}{\langle\bar{s}\rangle}
$$

which is a dimensionless measure of the spatial dispersion of a flow variable $s$ about its mean value. Based on time series in Figures $3 \mathrm{a}$ and $3 \mathrm{~b}$, the daytime (chosen for runs with $H>30 \mathrm{~W} \mathrm{~m}^{-2}$ ) averaged $C V(s)$ for $\sigma_{u}=\sqrt{\overline{u^{\prime} u^{\prime}}}, \sigma_{w}=\sqrt{\overline{w^{\prime} w^{\prime}}}$, $u_{*}, \sigma_{T}=\sqrt{\overline{T^{\prime} T^{\prime}}}, H, L E$, and $F_{c}$ are 0.11, 0.06, 0.16, 0.10, 0.17, 0.33, and 0.27, respectively. From this analysis, it is clear that $\sigma_{w}$ is the most uniform RSL flow variable. Based on the comparisons from the Appendix, differences between the CSAT3 and the ATI sonic anemometer measured $\sigma_{w}$ was $4 \%$, which is comparable with the observed 6\% $C V$ from this experiment. Hence, $\sigma_{w}$ variability in the $x-y$ plane can be neglected in a first-order analysis of RSL turbulence.

In terms of vertical fluxes, $H$ and $u_{*}$ have large but comparable spatial variability $(\sim 17 \%)$ though this variability is not entirely spatial. It is important to note that differences in CSAT3 and ATI-measured $u_{*}$ were approximately $8 \%$ and account for perhaps as much as $50 \%$ of the observed spatial variability. Nonetheless, the near equality in the $C V$ s between $H$ and $u_{*}$ brings about important implications on the spatial similarity in heat and momentum transport. Given that $u_{*}=\sqrt{-\overline{u^{\prime} w^{\prime}}}$ (i.e., directly proportional to the square root of a second-order statistic) and sensible heat is directly related to a second-order statistic suggests a spatial dissimilarity in eddies responsible for the vertical transport of heat and momentum. Care should be exercised when interpreting differences in momentum and scalar flux $C V$ s. Lenschow and Kristensen (1985) and Ritter et al. (1990) suggest that errors in the local momentum flux $\left(\overline{u^{\prime} w^{\prime}}\right)$ measurement for finite $(\sim 30 \mathrm{~min})$ averaging intervals are about twice the errors in scalar fluxes. Such increased measurement errors in $\overline{u^{\prime} w^{\prime}}$ due to the finite sampling period may partially explain why the $C V \mathrm{~s}$ in 
momentum flux are larger than sensible heat flux (vis-à-vis differences in transport characteristics).

The mass flux $C V$ was much larger than the sensible heat $C V$, suggesting that heat may appear more uniformly transported than water vapour or $\mathrm{CO}_{2}$. To interpret differences between heat and mass transport, consider the relationship between the turbulent flux above the canopy and local sources and sinks from the canopy foliage. In a one-dimensional approximation,

$$
{\overline{w^{\prime} s^{\prime}}}_{(z=h)}=\int_{0}^{h} S_{S}(z) \mathrm{d} z+{\overline{w^{\prime} s^{\prime}}}_{(z=0)}
$$

where $\overline{w^{\prime} s^{\prime}}$ and $S_{s}$ are the local flux and source (or sink) density per unit depth of a scalar entity $s$ emitted or absorbed by the foliage. The sources (or sinks) of water vapour (and $\mathrm{CO}_{2}$ ) from pine needles are controlled by both stomatal and boundary-layer conductance, whereas the transport of heat is only controlled by boundary-layer conductance. Additionally, the ground flux $\left(\overline{w^{\prime} s^{\prime}}(z=0)\right.$ contributes significantly to the above-canopy $\mathrm{CO}_{2}$ and water vapour when compared to heat. Hence, differences in $C V$ between $H$ and $L E$ may be interpreted through the added stomatal regulation variability and ground flux differences.

Also, daytime $C V \mathrm{~s}$ for $\sigma_{u}$ and $\sigma_{T}$ are, for all practical purposes, identical $(\sim 10 \%)$. Much of the measured $C V$ in $\sigma_{u}$ and $\sigma_{T}$ cannot be attributed to instrumentation differences (maximum $\sim 2 \%$ ). Recall that the longitudinal velocity and temperature spectra close to the canopy-atmosphere interface are strongly influenced by inactive eddies (Katul et al., 1998). Inactive eddy motion is a larger-scale $(\gg h)$ quasi-horizontal eddy motion that does not contribute significantly to vertical transport (Townsend, 1976; Katul et al., 1996b, 1998). Typically, inactive eddies have a characteristic length scale comparable to the height of the atmospheric boundary layer $(\approx 1 \mathrm{~km})$. Such a length scale is of the same order as the total length of the pine forest stand. Hence, the near equality in $\sigma_{u}$ and $\sigma_{T} C V \mathrm{~s}$ suggests that the same larger-scale eddy motion phenomenon governs the spatial variability of these two flow variables.

What is also evident from Figures $3 \mathrm{a}$ and $3 \mathrm{~b}$ is that the $C V$ for a flow variable $s$ cannot be the same for all runs and varies with time. However, a limitation to using $C V$ for all the runs in Figures $3 a$ and $3 b$ is that the $C V$ is ill defined when $\langle\bar{s}\rangle \rightarrow 0$ (e.g., for evening runs for scalar fluxes). To circumvent this limitation, another relative spatial variation parameter $(R V)$ given by

$$
R V(s)=\frac{\sqrt{\left\langle\bar{s}^{\prime \prime 2}\right\rangle}}{|\langle\bar{s}\rangle|+\sqrt{\left\langle\bar{s}^{\prime \prime 2}\right\rangle}}
$$

is proposed and used instead of the traditional $C V$. Note that $R V$ has many desirable limits for our analysis since $R V \rightarrow 0$ when $\left\langle\bar{s}^{\prime \prime 2}\right\rangle^{1 / 2} \rightarrow 0$ (but for $\langle\bar{s}\rangle \neq 0$ ), $R V \rightarrow 1$ when $\langle\bar{s}\rangle \rightarrow 0$, and $R V$ is well bounded between $[0,1]$. Hence, a flow 
TURBULENT FLUXES IN THE ROUGHNESS SUBLAYER OF AN EVEN-AGED PINE FOREST 11
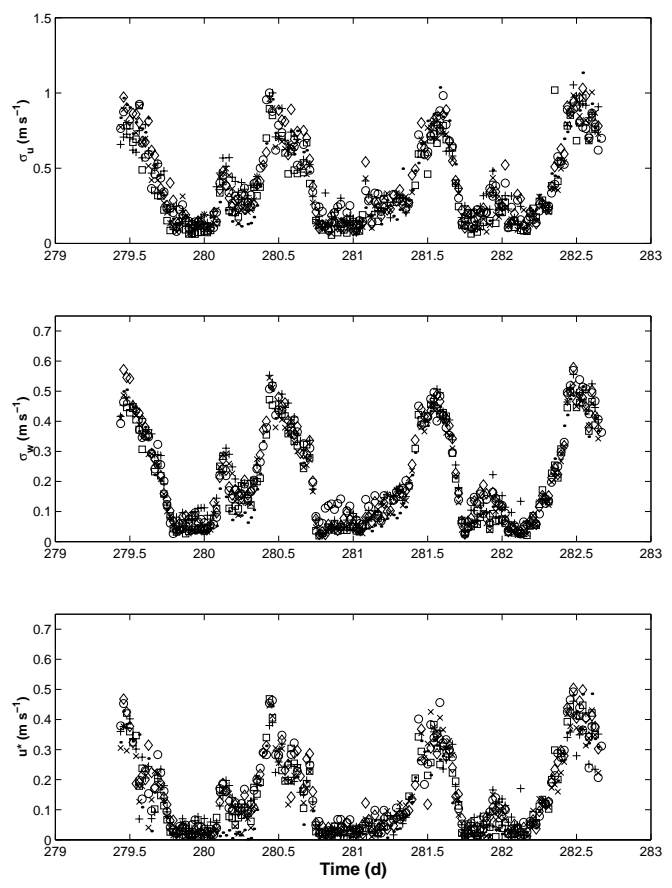

(a)
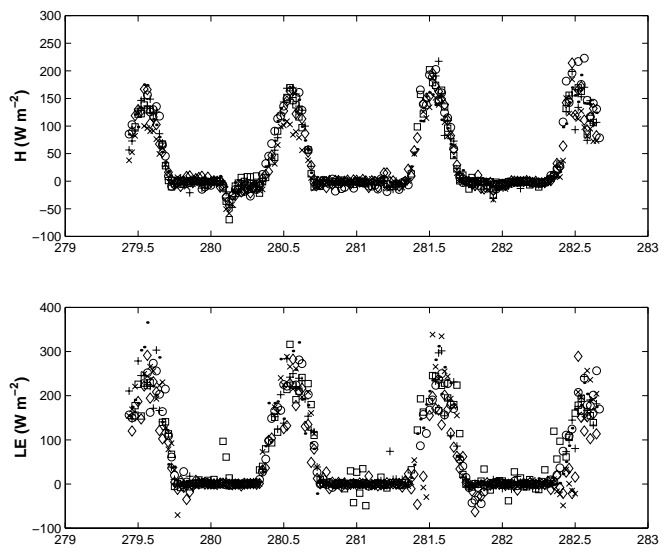

(b)

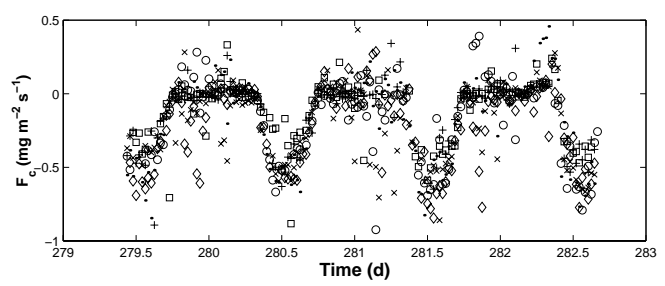

Figure 3. (a) Time series variation of $\sigma_{u}, \sigma_{w}$, and $u_{*}$ for Rings $1,3,4,5,6$, and 7. The symbols are identical to Figure 2. (b) Same as Figure 3a but for $H, L E$, and $F_{c}$. 
variable $s$ with large spatial variability but small mean value yields $R V$ close to unity, and a flow variable that is planar homogeneous yields a small $R V$. A flow variable with a spatial mean comparable to its spatial standard deviation yields an $R V$ close to 0.5 . Using the $R V$, we investigate how different turbulence conditions influence the temporal changes of the spatial variability of all RSL turbulent flow variables.

Near the canopy-atmosphere interface $(z / h \sim 1.0-1.2)$, the mechanical production of turbulence $\left(\propto\left\langle u_{*}\right\rangle^{3}\right)$ is the largest contributor to the turbulent kinetic energy (TKE) budget balancing the divergent vertical turbulent transport and viscous dissipation terms. Of the three velocity variances defining the TKE $(=0.5$ $\left[\sigma_{u}^{2}+\sigma_{v}^{2}+\sigma_{w}^{2}\right]$ ), the largest contributor is $\sigma_{u}$ (indicated by slopes in Table II). As demonstrated by Raupach et al. (1996) and Katul et al. (1998), the spectrum of $u^{\prime}$ at low frequencies is controlled by inactive eddy motion. For this stand, as $\left\langle u_{*}\right\rangle$ increases, the frequency of occurrence of inactive eddy motion $\left(\sim\left\langle u_{*}\right\rangle / h_{b}\right)$ also increases, where $h_{b}$ is the ABL height. Since inactive eddies close to $z / h=1$ introduce a large horizontal length scale (characterized by $h_{b}$ ), these eddies tend to better aggregate (i.e., mix) local sources (or sinks) for scalars and momentum in the $x, y$ plane. Hence, it is expected that $R V$ decreases for increasing $\left\langle u_{*}\right\rangle$ until some limiting $R V$ is attained that reflects inherent 'forest-scale' variability. The latter variability exists at scales much larger than the characteristic length scale of energetic eddies responsible for much of the vertical transport $(\sim h)$.

In Figures $4 \mathrm{a}$ and $4 \mathrm{~b}$, the $R V$ for variances $\left(\sigma_{u}, \sigma_{w}, \sigma_{T}\right)$ and turbulent fluxes $\left(\overline{w^{\prime} u^{\prime}}, \overline{w^{\prime} T^{\prime}}, \overline{w^{\prime} q^{\prime}}, \overline{w^{\prime} c^{\prime}}\right)$ as a function of $\left\langle u_{*}\right\rangle^{3}$ is shown. Note that, for $\left\langle u_{*}\right\rangle^{3}$ smaller that $0.02 \mathrm{~m}^{3} \mathrm{~s}^{-3}$ (or $\left\langle u_{*}\right\rangle 0.27 \mathrm{~m} \mathrm{~s}^{-1}$ ), the $R V$ rapidly increases with decreasing $\left\langle u_{*}\right\rangle^{3}$. However, for $\left\langle u_{*}\right\rangle^{3}$ exceeding $0.02 \mathrm{~m}^{3} \mathrm{~s}^{-3}$ the $R V$ for all variables approaches a near-constant minimum limit. While the above argument is a reasonable hypothesis to explain the dependence of $R V$ on $\left\langle u_{*}\right\rangle$, an equally plausible hypothesis is the dependence of sampling statistics on $u_{*}$. Higher values of $u_{*}$ results in more turbulent events passing through the sampling point which, in turn, leads to a reduction in the standard error of estimate of the mean. Hence, the reduction of $R V$ with $u_{*}$ may be attributed to sampling errors vis-à-vis the turbulent transport mechanisms.

\subsection{HOMOGENEITY OF SIMILARITY RELATIONSHIPS}

In the previous section, it was demonstrated that variances and fluxes do vary in $(x, y)$ within the RSL. However, this variation does not necessarily imply that single-tower measurements do not scale locally in accordance with canonical similarity structure of RSL turbulent transport. The small variation of both variances and fluxes over such large distances $(>100 \mathrm{~m}$ ) suggests that RSL flows may be in a state of 'moving equilibrium'. The 'moving equilibrium' concept, first proposed by Yaglom (1979) for $u_{*}$, states that if $u_{*}$ varies slowly in the $x, y$ plane (see e.g., Yaglom, 1979; Raupach et al., 1991), then $u_{*}$ can be considered as a local velocity 
TURBULENT FLUXES IN THE ROUGHNESS SUBLAYER OF AN EVEN-AGED PINE FOREST 13
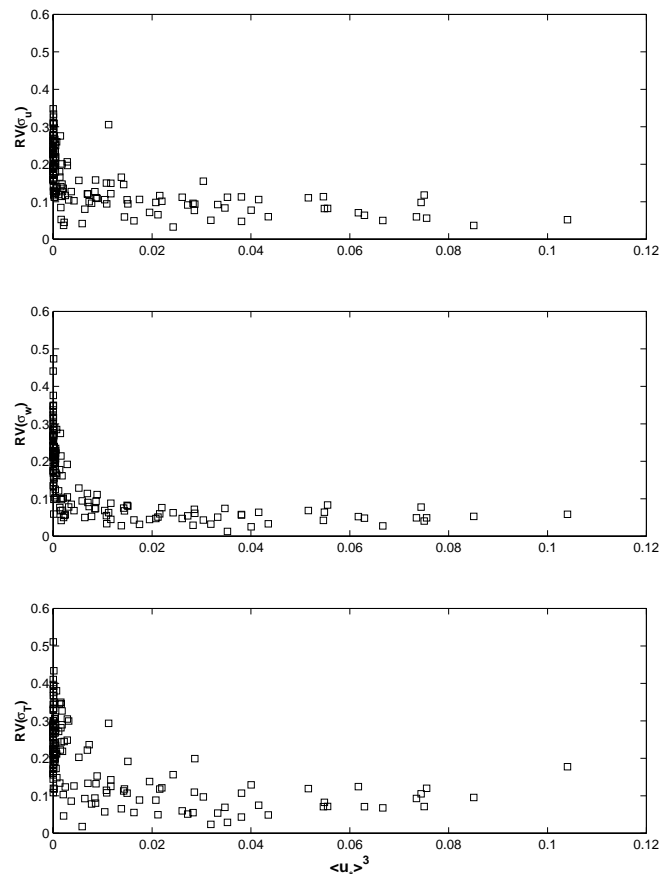

(a)
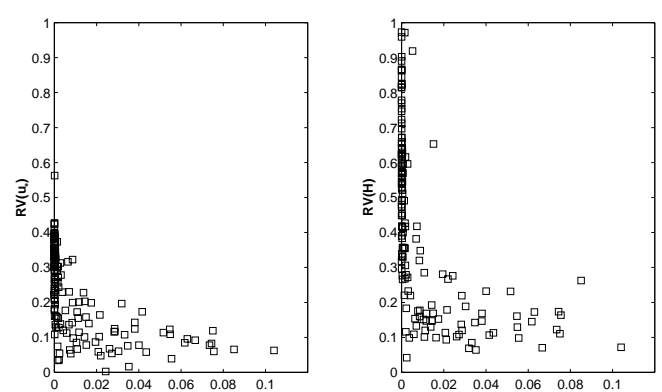

(b)
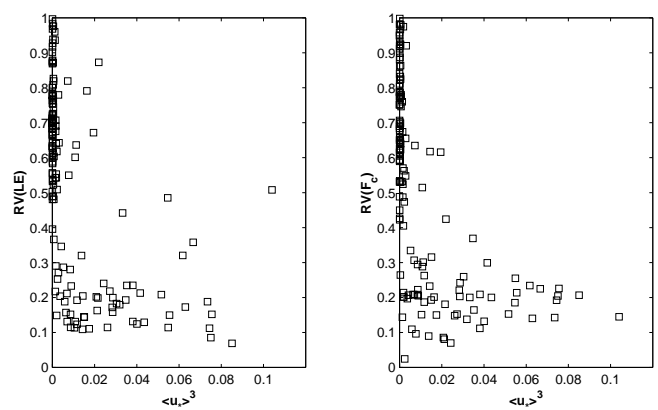

Figure 4. (a) Variation of $R V\left(\sigma_{u}\right), R V\left(\sigma_{w}\right), R V\left(\sigma_{T}\right)$ with $\left\langle u_{*}\right\rangle^{3}$ for day time and night time runs. (b) Same as Figure 4a but for $R V\left(u_{*}\right), R V(H), R V(L E)$, and $R V\left(F_{c}\right)$. The $R V(s)$ for a flow variable $s$ is computed using Equation (2). 
TABLE II

Regression analysis of turbulent velocity standard deviations $\left(\sigma_{u}, \sigma_{w}\right)$ as a function of friction velocity $\left(u_{*}\right)$ for all Rings. The regression model is of the form: $\sigma=A u_{*}+B$. The coefficient of determination $\left(R^{2}\right)$, the standard error of estimate (SEE), and the number of runs used in the regression $(N)$ are presented. The second line for each ring are for regression forced through the origin $(B=0)$.

\begin{tabular}{|c|c|c|c|c|c|c|}
\hline Variable & Ring \# & Slope $A$ & Intercept $B$ & $R^{2}$ & SEE & $N$ \\
\hline \multirow[t]{12}{*}{$\sigma_{w}$} & \multirow[t]{2}{*}{1} & 1.06 & 0.05 & 0.91 & 0.04 & \multirow[t]{2}{*}{358} \\
\hline & & 1.25 & 0.00 & 0.86 & 0.06 & \\
\hline & \multirow[t]{2}{*}{3} & 1.11 & 0.04 & 0.90 & 0.05 & \multirow[t]{2}{*}{175} \\
\hline & & 1.25 & 0.00 & 0.86 & 0.05 & \\
\hline & \multirow[t]{2}{*}{4} & 1.14 & 0.04 & 0.87 & 0.06 & \multirow[t]{2}{*}{149} \\
\hline & & 1.30 & 0.00 & 0.84 & 0.06 & \\
\hline & \multirow[t]{2}{*}{5} & 1.13 & 0.04 & 0.89 & 0.05 & \multirow[t]{2}{*}{148} \\
\hline & & 1.29 & 0.00 & 0.86 & 0.05 & \\
\hline & \multirow[t]{2}{*}{6} & 1.10 & 0.04 & 0.90 & 0.05 & \multirow[t]{2}{*}{150} \\
\hline & & 1.26 & 0.00 & 0.86 & 0.05 & \\
\hline & \multirow[t]{2}{*}{7} & 1.26 & 0.04 & 0.91 & 0.05 & \multirow[t]{2}{*}{127} \\
\hline & & 1.43 & 0.00 & 0.89 & 0.05 & \\
\hline \multirow[t]{12}{*}{$\sigma_{u}$} & \multirow[t]{2}{*}{1} & 1.83 & 0.15 & 0.87 & 0.10 & \multirow[t]{2}{*}{358} \\
\hline & & 2.40 & 0.00 & 0.71 & 0.14 & \\
\hline & \multirow[t]{2}{*}{3} & 1.82 & 0.09 & 0.88 & 0.09 & \multirow[t]{2}{*}{175} \\
\hline & & 2.19 & 0.00 & 0.82 & 0.11 & \\
\hline & \multirow[t]{2}{*}{4} & 1.97 & 0.11 & 0.86 & 0.10 & \multirow[t]{2}{*}{149} \\
\hline & & 2.41 & 0.00 & 0.79 & 0.13 & \\
\hline & \multirow[t]{2}{*}{5} & 1.98 & 0.10 & 0.88 & 0.09 & \multirow[t]{2}{*}{148} \\
\hline & & 2.40 & 0.00 & 0.81 & 0.12 & \\
\hline & \multirow[t]{2}{*}{6} & 1.81 & 0.12 & 0.86 & 0.09 & \multirow[t]{2}{*}{150} \\
\hline & & 2.26 & 0.00 & 0.77 & 0.12 & \\
\hline & \multirow[t]{2}{*}{7} & 1.96 & 0.13 & 0.86 & 0.10 & \multirow[t]{2}{*}{127} \\
\hline & & 2.50 & 0.00 & 0.75 & 0.13 & \\
\hline
\end{tabular}

scale independent of $(x, y)$ for small perturbations in the $x-y$ plane. That is, the forest stand can be decomposed into planar homogeneous patches, with each patch characterized by its own $h$ and $u_{*}$ as length and velocity scales. 
A direct consequence of the moving equilibrium assumption is that when local flow variables are properly normalized by local length and velocity scales, their variability in the $(x, y)$ plane becomes insignificant. For example, in the RSL,

$$
\frac{\sigma_{u}}{u_{*}}=A_{u}, \quad \frac{\sigma_{w}}{u_{*}}=A_{w}, \quad \frac{\sigma_{T}}{T_{*}}=A_{T}(\xi)^{-1 / 3},
$$

for $\xi>0$

$$
\xi=-\frac{z-d}{L}
$$

In (3), $T_{*}$ is a temperature scale defined as $T_{*}=\overline{w^{\prime} T^{\prime}} / u_{*}$ and $L$ and $d$ are the Obukhov length and zero-plane displacement heights, respectively, $A_{u}, A_{w}$, and $A_{T}$ are similarity constants and must be independent of $(x, y)$ by the moving equilibrium hypothesis. Here, the zero-plane displacement was computed for each Ring from the mean height of momentum absorption by the local leaf area density (see Thom, 1971) and was found to vary from 0.59 to $0.65 \mathrm{~h}$. The momentum absorption was computed from modelled $\overline{u^{\prime} w^{\prime}}$ profiles using the second-order closure model described in Katul and Albertson (1998). Figure 5 presents measured $\sigma_{u}$ and $\sigma_{w}$ as a function of measured $u_{*}$, and measured $T_{*}$ as a function of measured $\xi$ for all the Rings. The lines in the figure are 'best-fit' to Raupach et al.'s (1996) data for velocity, and 'best-fit' atmospheric surface-layer (ASL) data for temperature.

If single-tower measurements obey the RSL similarity structure, then $A_{u}, A_{w}$, and $A_{T}$ cannot be dependent on position in the $(x, y)$ space. For each Ring, $A_{u}, A_{w}$, and $A_{T}$ were computed and presented in Table II for momentum and in Table III for heat. Due to differences in flow rate, tube length, and tube diameter within the gas analyzer setup (see Table I), we did not perform a similar analysis for $c$ and $q$ given the significant spectral contribution of high frequency events to the overall scalar variances (see Section A.3 in Appendix A). Based on the regression analysis of Tables II and III, we found that the spatially averaged $A_{u}=1.90$ ( \pm $0.075), A_{w}=1.14( \pm 0.065)$, and $A_{T}=1.12( \pm 0.04)$. These velocity similarity constants are in good agreement with $A_{u}=1.8$ and $A_{w}=1.1$ reported by Raupach et al. (1996) for a laboratory RSL wind-tunnel experiment. In addition, Table III demonstrates that measured $\sigma_{T} / T_{*}$ exhibits a strong $-1 / 3$ power law (i.e., $\xi^{-1 / 3}$ ) dependence for all Rings. That is, the $-1 / 3$ power-law also does not vary in the $x-y$ plane. The occurrence of a $-1 / 3$ power law is commonly associated with 'free-convection' with $\sigma_{T}$ becoming independent of $u_{*}$, but strongly dependent on sensible heat $H$ (Albertson et al., 1995; Hsieh and Katul, 1997). The measured $A_{T}$ is in close agreement with atmospheric surface-layer values $\left(A_{T}=0.97\right)$ reported by Albertson et al. (1995), Katul et al. (1995), and Hsieh et al. (1996). We also did not find statistically significant differences between the individual Ring $A_{u}, A_{w}$, and $A_{T}$ at the $95 \%$ confidence limits. The significance tests were referenced to Ring 4 since $A_{w}$ and $A_{u}$ for Ring 4 are closest to the spatially averaged $A_{u}$ and $A_{w}$ 

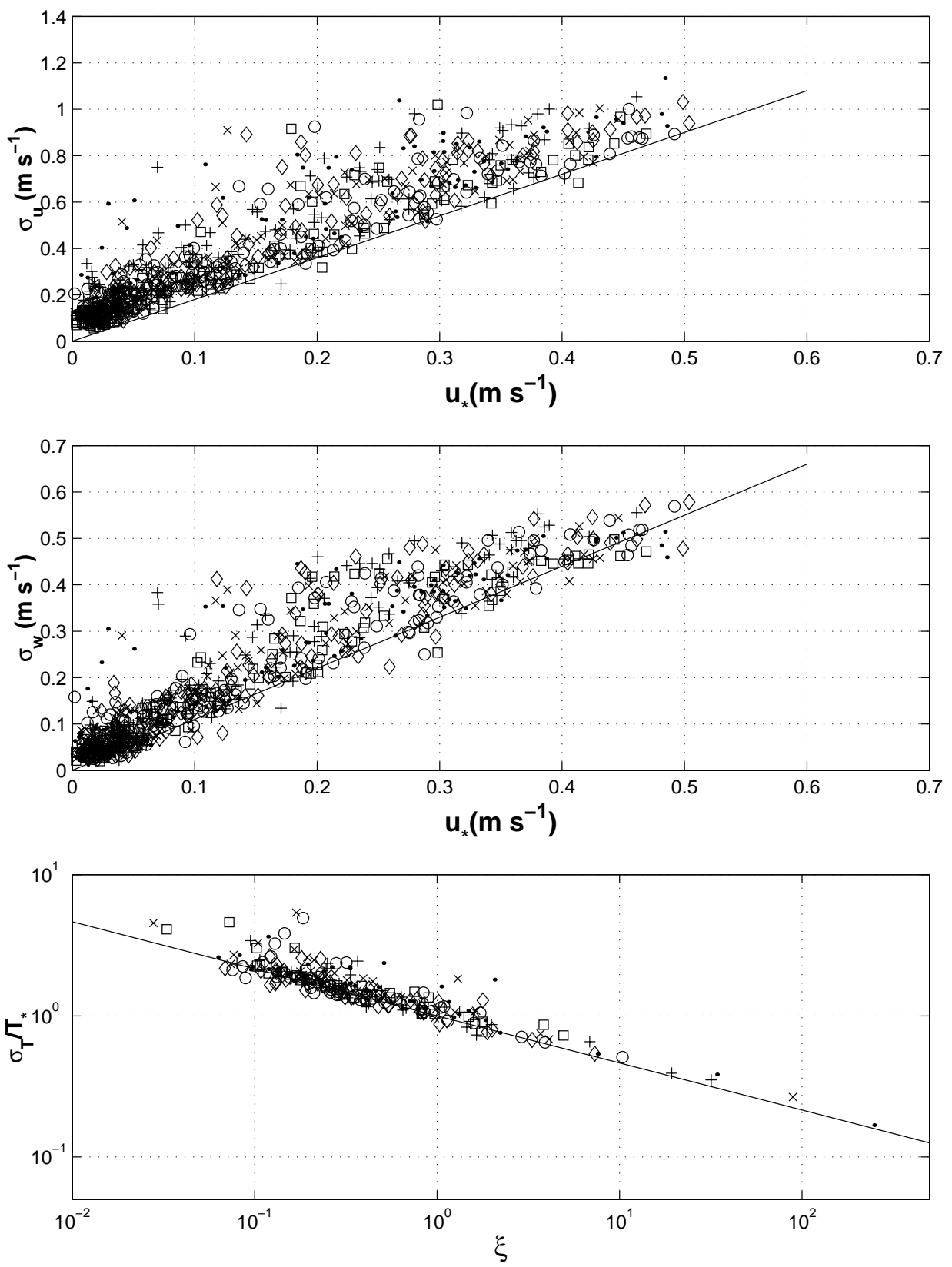

Figure 5. The variation of $\sigma_{u}$ and $\sigma_{w}$ with $u_{*}$ is shown for Rings 1, 3, 4, 5, 6, and 7 and all runs. The solid lines are best-fit regressions (i.e., $A_{u}=1.8, A_{w}=1.1$ ) to measurements from Raupach et al. (1996). The variation of $\sigma_{T} / T_{*}$, with the stability parameter $\xi$ is shown for daytime conditions (i.e., $H>30 \mathrm{~W} \mathrm{~m}^{-2}$ ) only. The solid line is $\sigma_{T} / T_{*}=1.0 \xi^{-1 / 3}$. Symbols are the same as in Figure 2. 
TABLE III

Regression analysis of normalized temperature standard deviation $\left(\sigma_{T} / T_{*}\right)$ as a function of the stability parameter $\xi=-(z-d) / L$ for all Rings and daytime conditions $\left(H>30 \mathrm{~W} \mathrm{~m}^{-2}\right)$. The regression model is of the form: $\ln \left(\sigma_{T} / T_{*}\right)=A \ln (\xi)+B$. The coefficient of determination $\left(R^{2}\right)$ and the standard error of estimate (SEE) along with the intercept $B$ are shown. The intercept $B$ is used to calculate the similarity constant $A_{T}$ of Equation (3) and is presented in brackets. In the $\mathrm{ASL}, A_{T}=1$.

\begin{tabular}{llllll}
\hline Ring \# & $n$ & Slope $A$ & Intercept $B /\left(A_{T}\right)$ & $R^{2}$ & SEE \\
\hline 1 & 50 & -0.32 & $0.16(1.18)$ & 0.87 & 0.18 \\
3 & 38 & -0.33 & $0.10(1.11)$ & 0.89 & 0.13 \\
4 & 46 & -0.32 & $0.06(1.06)$ & 0.83 & 0.14 \\
5 & 46 & -0.33 & $0.17(1.19)$ & 0.81 & 0.21 \\
6 & 46 & -0.34 & $0.10(1.11)$ & 0.72 & 0.24 \\
7 & 42 & -0.34 & $0.09(1.10)$ & 0.90 & 0.15 \\
\hline
\end{tabular}

for this stand. Finally, we note that the spatial coefficient of variation for $A_{u}, A_{w}$, and $A_{T}(4.0 \%, 5.8 \%$, and $3.9 \%$, respectively) are close to the reported magnitude of instrumentation measurement differences for $\sigma_{w}$ presented in Appendix A ( $\left.\sim 4 \%\right)$. Hence, the invariance of $A_{u}, A_{w}$, and $A_{T}$ in the $x-y$ plane is consistent with the 'moving equilibrium' hypothesis.

\subsection{CANOPY MORPHOLOGY AND INTEGRAL TIME SCALES}

Estimating RSL characteristic length or time scales from single-point measurements is commonly performed via the integral time scale $\left(I_{w}\right)$ defined as

$$
\begin{aligned}
& I_{w}=\int_{0}^{\infty} \rho_{w}(\tau) \mathrm{d} s ; \\
& \rho_{w}(\tau)=\frac{\overline{w^{\prime}(t+\tau) w^{\prime}(t)}}{\sigma_{w}^{2}}
\end{aligned}
$$

where $\rho_{w}(\tau)$ is the vertical velocity auto-correlation function, and $\tau$ is the time lag. In practice, the integration of $\rho_{w}(\tau)$ is terminated at the first zero crossing as discussed in Katul et al. (1997a). In RSL turbulence, $I_{w}$ represents the characteristic time scale of 'active' eddies responsible for much of the scalar transport.

To derive similarity relationships for $I_{w}$, we consider the mixing-layer analogy of Raupach et al. (1996). Raupach et al. (1996) argued that vertical transport close 
to the canopy-atmosphere interface resembles a mixing layer rather than a boundary layer because the canopy-atmosphere interface is a porous medium and cannot impose the same severe constraint on fluid continuity (i.e., the no-slip boundary condition) as an impervious boundary. A mixing layer is a boundary-free shear flow formed in a region between two co-flowing fluid streams of different velocity but the same density. The resemblance between canopy-atmosphere vertical transport and a mixing layer is mainly attributed to the strong inflection point in the mean velocity profile at $z / h=1$. Such an inflection point in $\bar{u}(z)$ leads to the generation of two-dimensional Kelvin-Helmholtz $(\mathrm{KH})$ instabilities with a streamwise wavelength $\left(\Lambda_{x}\right)$.

Using the mixing-layer analogy of Raupach et al. (1996), $I_{w}$ can be related to the characteristic frequency of $\mathrm{KH}$ instabilities, after some algebraic manipulation, using

$$
\frac{1}{I_{w}}=A_{m} \frac{\bar{u}}{h}
$$

where $A_{m} \approx 2.84$ estimated by use for the 'generic canopy' data in Raupach et al. (1996) with $\bar{u}$ defined at $z / h=1$. Table IV presents the measured $A_{m}$ for each Ring obtained by regressing measured $I_{w}^{-1}$ versus measured $\bar{u} / h$ shown in Figure 6. We restricted the analysis in Table IV and Figure 6 to $H>30 \mathrm{~W} \mathrm{~m}^{-2}$ so that daytime runs are included for each Ring. Uncertainty in computed $I_{w}$ as well as the existence of factors other than $\bar{u} / h$ that strongly influences $I_{w}$ precluded investigating (5) for evening runs (not shown in Figure 6).

From our measurements, the spatially averaged $A_{m}$ value of $2.18( \pm 0.17)$ is found to be lower than the value determined from Raupach et al.'s (1996) data (shown as the solid line in Figure 6). This is not surprising since Raupach et al. (1996) estimated $A_{m}$ at $z=h$, while the measurements from this experiment are for $z / h=1.11$ (except for Ring $7, z / h=1.29$ ). Given that $I_{w}$ does not vary appreciably with $z$ for $z / h=1.0-1.5$, as $z / h$ increases, $\bar{u}$ increases leading to a reduction in $A_{m}$ (Kaimal and Finnigan, 1994; Thompson, 1979). For Ring 7 , we present both raw $A_{m}$ values obtained for $z / h=1.28$ and adjusted $A_{m}$ for $z / h=1.11$. The adjustment in Ring 7 is based on a logarithmic interpolation of $\bar{u}$ at $z=15.5 \mathrm{~m}$ from measured $\bar{u}$ at $z=18 \mathrm{~m}$.

While the spatial variation in $A_{m}$ is not large (spatial coefficient of variation is $8 \%$ for an $18 \%$ variation in LAI), it is sufficiently significant to warrant further analysis. Irvine and Brunet (1996) demonstrated that $A_{m}$ does not vary with atmospheric stability. Hence, it is unlikely that Ring-to-Ring variations in $A_{m}$ are caused by the spatial variability in flow properties such as sensible heat and friction velocity. The conclusions from Irvine and Brunet (1996) lead us to consider canopy morphology (particularly LAI) as a source of variability. The potential dependence of $A_{m}$ on LAI seems plausible. For small LAI (but the same canopy height $h$ ), the instabilities close to the canopy-atmosphere interface are not KH produced and the flow resembles a boundary layer (vis-à-vis a mixing layer) in which no inflection 


\section{TABLE IV}

Regression analysis to determine $A_{m}$ (in $\left.I_{w}^{-1}=A_{m} \bar{u} / h\right)$ for all Rings and for $H>$ $30 \mathrm{~W} \mathrm{~m}^{-2}$. The coefficient of determination $\left(R^{2}\right)$ and the standard error of estimate (SEE) are also presented. The measured leaf area index (LAI) around the central tower of each Ring is also shown. The values for Ring $7^{*}$ are adjusted values of Ring 7 to reflect $\bar{u}$ measured at $15.5 \mathrm{~m}$ rather than $18 \mathrm{~m}$ as in Ring 7. This adjustment assumes that $\bar{u}$ varies logarithmically between $z=15.5 \mathrm{~m}$ and $z=$ $18 \mathrm{~m}$, and that the zero-plane displacement is $0.65 \mathrm{~h}$.

\begin{tabular}{lllll}
\hline Ring \# & $A_{m}$ & $R^{2}$ & SEE & LAI \\
\hline 1 & 1.82 & 0.54 & 0.05 & 2.65 \\
3 & 2.33 & 0.69 & 0.04 & 4.56 \\
4 & 2.14 & 0.67 & 0.05 & 3.09 \\
5 & 2.31 & 0.65 & 0.05 & 4.24 \\
6 & 2.21 & 0.40 & 0.07 & 3.58 \\
7 & 2.05 & 0.58 & 0.06 & 3.90 \\
$7^{*}$ & 2.28 & 0.58 & 0.06 & 3.90 \\
\hline
\end{tabular}

in $\bar{u}$ exists. Measurements by Paw $\mathrm{U}$ et al. (1992) over short vegetation, and the seasonal variation in measured $I_{w}$ and $\bar{u} / u_{*}$ by Lu and Fitzjarrald (1994), indirectly support this argument. For such boundary-layer flows, $I_{w}^{-1}$ becomes poorly correlated with $\bar{u} / h$ resulting in a small $A_{m}$. That is, for the same canopy height, a decrease in LAI results in a decrease in $A_{m}$. This experiment uniquely examined the dependence of $A_{m}$ on LAI for the same stand (i.e., tree height, tree architecture, pine needle sizes and orientation are all similar in this experiment) in Figure 7. Figure 7 clearly demonstrates that as LAI decreases, $A_{m}$ also decreases, confirming the above argument.

\section{Conclusions}

This study is the first to examine experimentally the spatial variability of turbulent statistics within the RSL above a tall even-aged forest. We demonstrated the following:

1. The velocity and temperature standard deviations $\left(\sigma_{u}, \sigma_{w}\right.$, and $\left.\sigma_{T}\right)$ are more planar homogeneous $(C V \sim 10 \%)$ than $u_{*}$ and sensible heat $(H)(C V \sim 17 \%)$. 


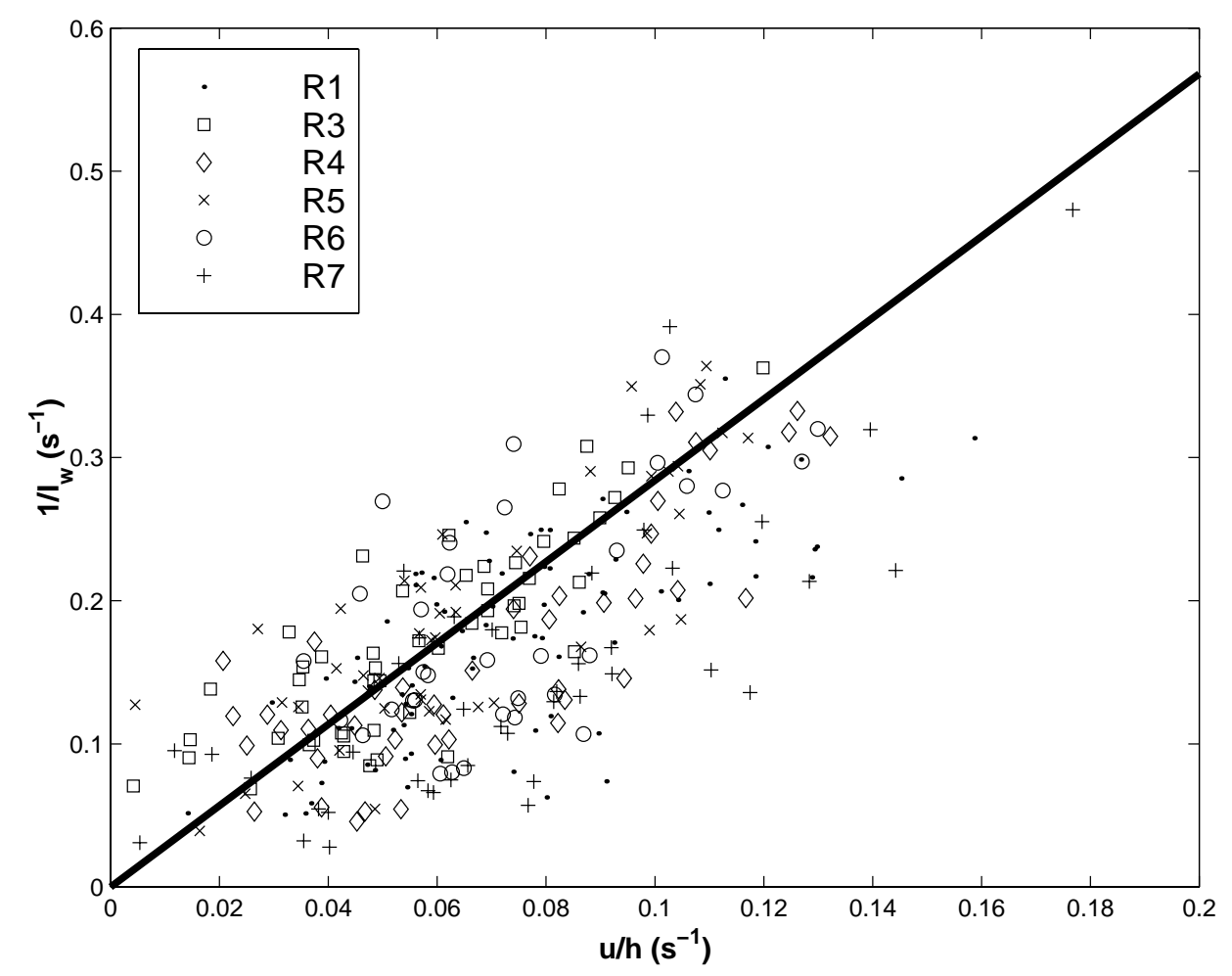

Figure 6. The variation of $I_{w}^{-1}$ with the arrival frequency $\bar{u} / h$ for Rings $1,3,4,5,6$, and 7 . The solid line is derived from the 'generic canopy' data of Raupach et al. (1996).

2. The sensible heat flux is more homogeneous than the fluxes of other scalar entities such as $\mathrm{CO}_{2}\left(F_{c}\right)$ and water vapour $(L E)$. This conclusion confirms earlier suggestions by Katul et al. (1995) and Andreas et al. (1998) that the flux of sensible heat appears more uniformly distributed than other scalars such as water vapour.

3. Single-tower measurements when scaled with local variables can represent the canonical structure of single-point turbulence statistics. Particularly, it is demonstrated that flux-variance similarity functions are independent of location.

4. The spatial variability of all RSL flow variables is not constant in time but strongly depends on $\left\langle u_{*}\right\rangle^{3}$. One possible explanation is that the increase in mechanical production of turbulent kinetic energy increases the frequency of inactive eddies. Such eddy motion introduces a horizontal length scale much larger than the canopy height $(h)$ that enhances aggregation of local sources and sinks near the canopy-atmosphere interface. Another equally plausible (and inter-related) explanation is that the reduction of $R V$ with $u_{*}$ may be attributed to the dependence of sampling errors on $u_{*}$. Future large eddy simu- 


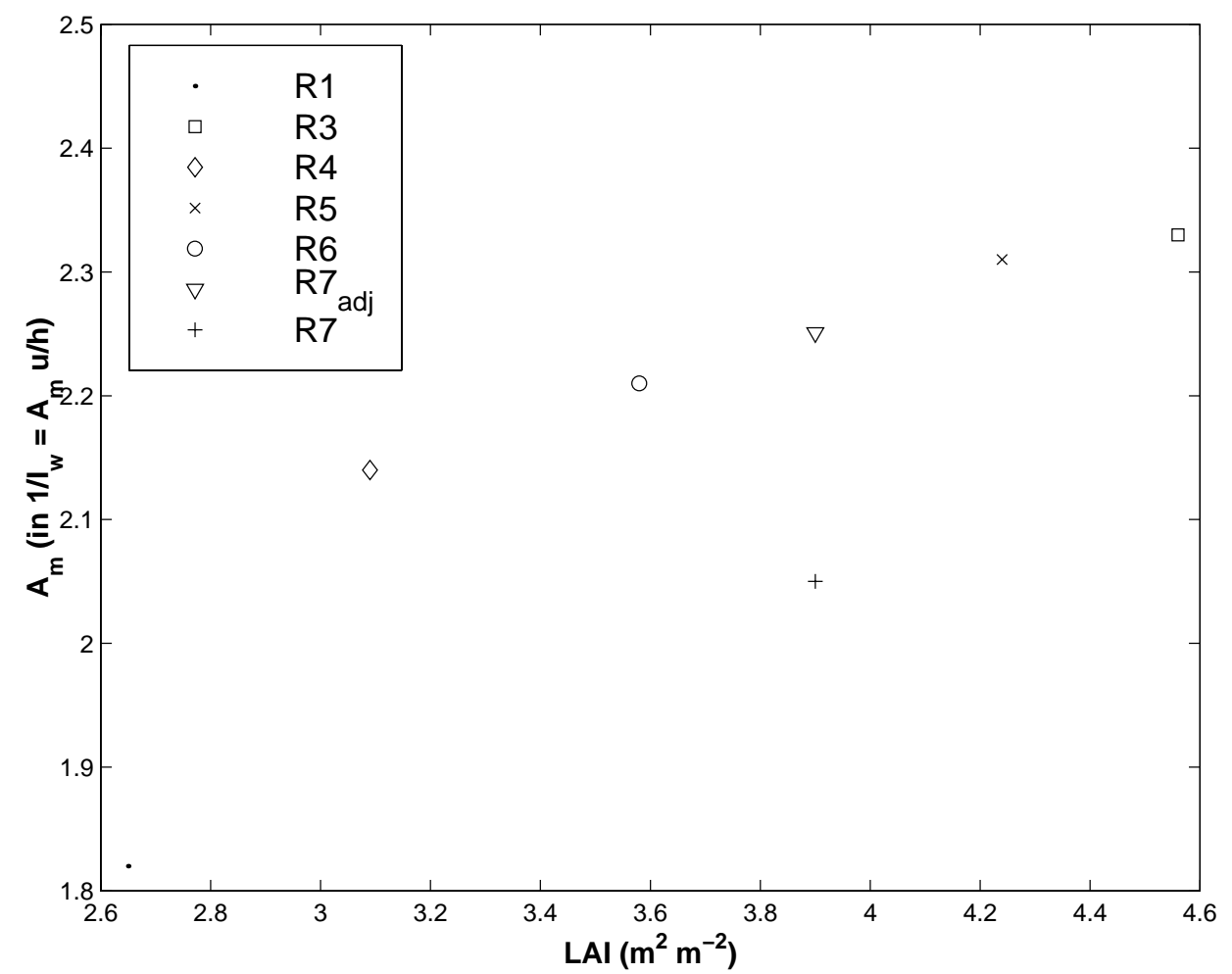

Figure 7. The dependence of $A_{m}$ on LAI for Rings 1, 3, 4, 5, 6, and 7. In Ring 7, the adjusted value $\left(\mathrm{R} 7^{\mathrm{adj}}\right.$ ) is refers to interpolating $\bar{u}$ from its $18.0 \mathrm{~m}$ measured value to $15.5 \mathrm{~m}$ logarithmically. This adjustment is necessary for consistency with the measurement heights of $\bar{u}$ for the other rings.

lation runs with different $u_{*}$ can provide systematic diagnostics as to which of these arguments better explains the dependence of $R V$ on $u_{*}$.

5. Flow properties derived from lagged correlation function analysis are more sensitive to the local variability in leaf area density when compared to other second-order statistics. Particularly, the local relationship between the reciprocal of the integral time scale $\left(I_{w}\right)$ and the arrival frequency of organized structures $(\bar{u} / h)$ predicted from the mixing-layer analogy of Raupach et al. (1996) exhibits dependence on the local leaf area index.

The broader implications of these findings to the measurement and modelling of RSL flows above uniform canopies (i.e., $C V(L A I)<20 \%$ ) are as follows:

1. The planar homogeneity assumption in $\sigma_{u}, \sigma_{w}, u_{*}$, and $H$ (or the atmospheric stability parameter) commonly employed in Lagrangian dispersion models to compute the source-weight function of scalar entities such as water vapour or $\mathrm{CO}_{2}$ in the roughness sublayer (e.g., Leclerc et al., 1988; Baldocchi, 1992; Katul et al., 1997a) is reasonable. 
2. The 'moving equilibrium' hypothesis, originally developed for surface-layer flows, can be extended to RSL flows as evidenced by conclusion 3. Strictly speaking, conclusion 3 is a necessary and not a sufficient condition. Nonetheless, agreement between the present measurements and wind-tunnel experiments (see Raupach et al., 1996; Raupach, 1988) suggest that the 'moving equilibrium' hypothesis is a practical approximation for the RSL. The 'moving equilibrium' hypothesis has direct consequences for the comparisons between closure-modelling calculations, which represent horizontally averaged flow statistics, and single-tower measurements. Horizontally averaged flow statistics computed from higher-order closure principles and normalized by $\left\langle u_{*}\right\rangle$ and $\langle h\rangle$ can be converted to 'local' flow statistics if the local length (e.g., $h$ ) and velocity scales (e.g., $u_{*}$ ) are used. Additionally, the planar homogeneity in $\sigma_{u}, \sigma_{w}, u_{*}$ indirectly supports the negligence of 'dispersive' fluxes arising from horizontal averaging of the time-averaged equations of motion (Finnigan, 1985) in RSL flows.

3. The planar homogeneity in $\sigma_{T}$, coupled with the invariance of the similarity relationship $\sigma_{T} / T_{*}=A_{T} \xi^{-1 / 3}$ in the $x-y$ plane, demonstrates that the fluxvariance method, developed for the atmospheric surface layer, can accurately reproduce the daytime sensible heat flux (of local relevance) from single-tower $\sigma_{T}$ measurements within the RSL.

4. The strong local relationship between $I_{w}^{-1}$ and $\bar{u} / h$ (i.e., $I_{w}^{-1}=A_{m} \bar{u} / h$ ) for all Rings suggests that the mixing-layer analogy for vertical transport near $z / h=1$ provides an analytic linkage between the 'origins' of organized motion and characteristic time scales for RSL transport. Local canopy morphology changes do not alter the functional relationship between $I_{w}^{-1}$ and $\bar{u} / h$ but can alter $A_{m}$.

5. When comparing net carbon uptake and water budgets between different ecosystems derived from single-tower measurements within each system, it is necessary to interpret budget differences that are less than $20 \%$ with great caution. As evidenced from this experiment, unless special care is taken in instrument calibration and cross comparison, it will be difficult to meaningfully evaluate budget differences smaller than $20 \%$. Additionally, because of their control by stomatal and boundary-layer conductances and the more complex nature of the sources and sinks (e.g., influence of soil), $L E$ and $F_{c}$ are inherently more spatially variable than $H$. This experiment demonstrated that at least $8 \%$ spatial variability in daytime $H$ is not uncommon.

\section{Acknowledgements}

The authors would like to thank Andrew Palmiatti, Galen Hon, and Greg Burkland for their help during the experiment. We also thank Betsy Nettleton for all her efforts in coordinating travel, lodging and equipment shipping for various inves- 
tigators, and George Hendrey and William Schlesinger for facilitating the use of the Free Air $\mathrm{CO}_{2}$ Enrichment Facilities (FACE) at Duke Forest. We also thank the two reviewers for their helpful comments and suggestions. Particularly, we thank the reviewers for pointing out the potential dependence of RV on $u_{*}$ due to sampling errors. This project was funded by the Department of Energy (DOE) through the National Institute for Global Environmental Change (NIGEC) through the SouthEast Regional Center at the University of Alabama, Tuscaloosa (DOE Cooperative agreement DE-FC03-90ER61010) and through the Office of Health and Environmental Research (DE- $\left.\mathrm{ACO}_{2}-76 \mathrm{CH} 00016\right)$, and the National Science Foundation (NSF-BIR 12333).

\section{Appendix A: Comparisons between Different Instruments}

In this appendix, the inter-comparison statistics for different eddy-covariance systems are reported.

\section{A.1. VELOCITY SENSORS}

Because three sonic types (ATI, GILL, and CSAT3) were used in this experiment, it was necessary to quantify differences in the statistics due to differences in sonic anemometer configurations. We compared the ATI, GILL, and CSAT3 velocity and temperature measurements side by side $(80 \mathrm{~cm}$ apart) using measurements from two experiments described next.

\section{A.1.1. ATI/CSAT3 Comparison (Table A.I)}

At Ring 2, 67 runs, each of 30-minute duration, were collected between Day of Year (DOY) 279 and 281 in which the CSAT3 and ATI were simultaneously measuring velocity and temperature at $10 \mathrm{~Hz}$. Table $\mathrm{V}$ reports the regression comparison between the two anemometers. The maximum variability between the anemometers was at most $4 \%$ (based on the slope of the regression analysis) for standard deviations, $9 \%$ for the friction velocity, and $8 \%$ for sensible heat.

\section{A.1.2. GILL/CSAT3 Comparison (Table A.II)}

At Ring 1, 87 runs, each of 30-minute duration, were collected between DOY 284 and 286 in which the CSAT3 and the GILL anemometers were simultaneously measuring velocity and temperature at $5 \mathrm{~Hz}$ and $10 \mathrm{~Hz}$, respectively. In this experiment, the system from Ring 4 was co-located with the setup at Ring 1. Table A.II reports the regression comparison between the two anemometers. The variability between the anemometers was at most $1 \%$ for all standard deviations, $1 \%$ for the friction velocity, and $4 \%$ for sensible heat. 
TABLE A.I

Comparisons between ATI and CSAT3 at Ring 2 (Day of Year 279-281/1997; number of runs $n=67$ ) using a linear regression model. The regression statistics for the relevant flow variables, including the coefficient of determination $\left(R^{2}\right)$ and the standard error of estimate (SEE), are shown. The independent and dependent variables are the ATI and CSAT3, respectively.

\begin{tabular}{lllll}
\hline Flow variable & Slope & Intercept & $R^{2}$ & SEE \\
\hline $\bar{u}\left(\mathrm{~m} \mathrm{~s}^{-1}\right)$ & 1.00 & 0.02 & 0.983 & 0.04 \\
$\bar{T}\left({ }^{\circ} \mathrm{C}\right)$ & 0.96 & 0.52 & 0.999 & 0.03 \\
$\sigma_{u}\left(\mathrm{~m} \mathrm{~s}^{-1}\right)$ & 0.98 & 0.00 & 0.999 & 0.02 \\
$\sigma_{v}\left(\mathrm{~m} \mathrm{~s}^{-1}\right)$ & 0.98 & 0.00 & 0.995 & 0.01 \\
$\sigma_{w}\left(\mathrm{~m} \mathrm{~s}^{-1}\right)$ & 1.04 & 0.00 & 1.000 & 0.00 \\
$\sigma_{T}\left({ }^{\circ} \mathrm{C}\right)$ & 0.99 & 0.00 & 0.990 & 0.02 \\
$u_{*}\left(\mathrm{~m} \mathrm{~s}^{-1}\right)$ & 0.91 & 0.00 & 0.901 & 0.02 \\
$H\left(\mathrm{~W} \mathrm{~m}^{-2}\right)$ & 1.08 & 0.50 & 0.997 & 2.40 \\
\hline
\end{tabular}

TABLE A.II

Comparisons between GILL and CSAT3 at Ring 1 (Day of Year 284-286/1997; number of runs $n=87$ ) using a linear regression model. The regression statistics for the relevant flow variables, including the coefficient of determination $\left(R^{2}\right)$ and the standard error of estimate (SEE), are shown. The independent and dependent variables are the GILL and CSAT3, respectively.

\begin{tabular}{lcccc}
\hline Flow variable & Slope & Intercept & $R^{2}$ & SEE \\
\hline $\bar{u}\left(\mathrm{~m} \mathrm{~s}^{-1}\right)$ & 0.93 & 0.17 & 0.968 & 0.08 \\
$\bar{T}\left({ }^{\circ} \mathrm{C}\right)$ & 1.26 & \multicolumn{1}{c}{-4.0} & 0.997 & 0.27 \\
$\sigma_{u}\left(\mathrm{~m} \mathrm{~s}^{-1}\right)$ & 0.99 & 0.03 & 0.993 & 0.02 \\
$\sigma_{v}\left(\mathrm{~m} \mathrm{~s}^{-1}\right)$ & 1.00 & 0.02 & 0.991 & 0.02 \\
$\sigma_{w}\left(\mathrm{~m} \mathrm{~s}^{-1}\right)$ & 1.04 & 0.00 & 0.999 & 0.01 \\
$\sigma_{T}\left({ }^{\circ} \mathrm{C}\right)$ & 1.00 & 0.05 & 0.990 & 0.02 \\
$u_{*}\left(\mathrm{~m} \mathrm{~s}^{-1}\right)$ & 1.01 & -0.01 & 0.980 & 0.02 \\
$H\left(\mathrm{~W} \mathrm{~m}^{-2}\right)$ & 1.04 & 0.53 & 0.990 & 7.05 \\
$L E\left(\mathrm{~W} \mathrm{~m}^{-2}\right)$ & 0.94 & 4.93 & 0.920 & 21.2 \\
$F_{c}\left(\mathrm{mg} \mathrm{m}^{-2} \mathrm{~s}^{-1}\right)$ & 0.87 & -0.01 & 0.910 & -0.08 \\
\hline
\end{tabular}


TABLE A.III

Comparisons between $\mathrm{KH} 2 \mathrm{O}$ and LICOR 6262 at Ring 7 (Day of Year 279-282/1997; number of runs $n$ $=100$ ) using a linear regression model. The regression statistics for the relevant flow variables, including the coefficient of determination $\left(R^{2}\right)$ and the standard error of estimate (SEE), are shown. The independent and dependent variables are the KH2O and LICOR 6262, respectively.

\begin{tabular}{lllll}
\hline Flow variable & Slope & Intercept & $R^{2}$ & SEE \\
\hline$\sigma_{q}\left(\mathrm{~g} \mathrm{~m}^{-3}\right)$ & 0.88 & -0.02 & 0.97 & 0.04 \\
$L E\left(\mathrm{~W} \mathrm{~m}^{-2}\right)$ & 0.92 & -3.59 & 0.99 & 10.9 \\
\hline
\end{tabular}

\section{A.2. EFFECts of tUbe LENGTh, DiAmeters, AND FlOW RATES}

Lenschow and Raupach (1991) demonstrated that the frequency $f_{o}$ above which significant attenuation occurs is:

$$
f_{o}=n_{o} \bar{u}(r X)^{-0.5}
$$

where $n_{o}$ is the normalized frequency, $r$ is the sampling tube radius, and $X$ is the distance travelled in the sampling tube. From Table I, the largest variation in system configuration is in $X$ and the setup of Rings 1 and 4 represent the two extremes. While the impact of tube attenuation at high frequencies $(f)$ is critical to scalar variances, it is less critical to scalar covariances. Recall that at high frequencies, scalar variances decay as $f^{-5 / 3}$ while scalar covariances decay as $f^{-7 / 3}$. A sideby-side comparison between $F_{c}$ and $L E$ is presented in Table A.II for the system configuration in Rings 1 and 4 (see Section A.1.2). The differences between systems are $6 \%$ for $L E$ and $13 \%$ for $F_{c}$ (primarily due to poor nighttime comparisons). If only daytime conditions are considered $\left(H>30 \mathrm{~W} \mathrm{~m}^{-2}\right)$, the $F_{c}$ differences are $9 \%$.

\section{A.3. COMPARISON BETWEEN KRYPTON HYGROMETER AND LICOR 6262 WATER VAPOUR CONCENTRATION (TABLE A.III)}

At Ring 7, simultaneous water vapour concentration measurements using a Campbell Scientific Krypton hygrometer (hereafter referred to as KH2O) and a LICOR 6262 infrared gas analyzer were available (101 runs). The KH2O was factorycalibrated just prior to the experiment. A comparison between these two systems allows the degree of concentration fluctuation attenuation by tubing for five of the six eddy-covariance systems to be assessed. It is evident from the comparison of Table A.III that the $\mathrm{KH} 2 \mathrm{O}$ standard deviation and latent heat fluxes were larger 
than their LICOR 6262 counterpart by 12, and 8\%, respectively. As expected, the $\mathrm{KH} 2 \mathrm{O}$ and LICOR 6262 fluxes are in closer agreement than the variances given the rapid decay of the $\overline{w^{\prime} q^{\prime}}$ covariance at high frequencies $\left(\sim f^{-7 / 3}\right)$ when compared to the variance decay $\left(\sim f^{-5 / 3}\right)$.

\section{References}

Albertson, J. D., Parlange, M. B., Katul, G. G., Chu, C. R., and Stricker, H.: 1995, 'Sensible Heat Flux Estimates for Arid Regions: A Simple Flux-Variance Method', Water Resour. Res. 31, 969-973.

Albini, F. A.: 1981, 'A Phenomenological Model for Wind Speed and Shear Stress Profiles in Vegetation Cover Layers', J. Appl. Meteorol. 20, 1325-1335.

Amiro, B. D.: 1990, 'Comparison of Turbulence Statistics within Three Boreal Forest Canopies', Boundary-Layer Meteorol. 51, 99-121.

Amiro, B. D. and Davis, P. A.: 1988, 'Statistics of Atmospheric Turbulence within a Natural Black Spruce Forest Canopy', Boundary-Layer Meteorol. 44, 267-283.

Andreas, E. L., Hill, R., Gosz, J., Moore, D., Otto, W., and Sarma, A.: 1998, 'Statistics of Surface Layer Turbulence over Terrain with Metre-Scale Heterogeneity', Boundary-Layer Meteorol. 86, 379-408.

Baldocchi, D. and Meyers, T. P.: 1989, 'The Effects of Extreme Turbulent Events of the Estimation of Aerodynamic Variables in a Decidous Forest Canopy', Agric. For. Meteorol. 48, 117-134.

Baldocchi, D. and Meyers, T. D.: 1988, 'Turbulence Structure in a Deciduous Forest', BoundaryLayer Meteorol. 43, 345-364.

Baldocchi, D.: 1992, 'A Lagrangian Random Walk Model for Simulating Water Vapour, $\mathrm{CO}_{2}$ and Sensible Heat Densities and Scalar Profiles over and within a Soybean Canopy', Boundary-Layer Meteorol. 61, 113-144.

Ellsworth, D. S., Oren, R., Huang, C., Phillips, N., and Hendrey, G.: 1995, 'Leaf and Canopy Responses to Elevated $\mathrm{CO}_{2}$ in a Pine Forest under Free-Air $\mathrm{CO}_{2}$ Enrichment', Oecologia 104, 139-146.

Ellsworth, D. S.: 1999, ' $\mathrm{CO}_{2}$ Enrichment in a Maturing Pine Forest: Are $\mathrm{CO}_{2}$ Exchange and Water Status in the Canopy Affected?', Plant, Cell Environ., in press.

Finnigan, J. J.: 1985 , 'Turbulent Transport in Flexible Plant Canopies', in B. A. Hutchinson and B. B. Hicks (eds.), The Forest-Atmosphere Interaction, D. Reidel Publishing Company, Dordrecht, pp. 443-480.

Hsieh, C. I., Katul, G. G., Scheildge, J., Sigmon, J. T., and Knoerr, K. R.: 1996, 'Estimation of Momentum and Heat Fluxes Using Dissipation and Flux-Variance Methods in the Unstable Surface Layer', Water Resour. Res. 8, 2453-2462.

Hsieh, C. I. and Katul, G. G.: 1997, 'The Dissipation Methods, Taylor's Hypothesis, and Stability Correction Functions in the Atmospheric Surface Layer', J. Geophys. Res. 102, 16,391-16,405.

Irvine, M. R. and Brunet, Y.: 1996, 'Wavelet Analysis of Coherent Eddies in the Vicinity of Several Vegetation Canopies', Phys. Chem. Earth 21, 161-165.

Kaimal, J. C. and Finnigan, J. J.: 1994, Atmospheric Boundary Layer Flows: Their Structure and Measurements, Oxford University Press, $289 \mathrm{pp}$.

Kaiser, J.: 1998, 'Climate Change - New Network Aims to Take the Worlds $\mathrm{CO}_{2}$ Pulse Source', Science 281, 506-507.

Katul, G. G., Geron, C., Hsieh, C. I., Vidakovic, B., and Guenther, A.: 1998, 'Active Turbulence and Scalar Transport near the Forest-Atmosphere Interface', J. Appl. Meteorol. 37, 1533-1546.

Katul, G. G. and Albertson, J. D.: 1998, 'An Investigation of Higher Order Closure Models for a Forested Canopy’, Boundary-Layer Meteorol. 89, 47-74. 
Katul, G. G., Oren, R., Ellsworth, D., Hsieh, C. I., and Phillips, N.: 1997a, 'A Lagrangian Dispersion Model for Predicting $\mathrm{CO}_{2}$ Sources, Sinks, and Fluxes in a Uniform Loblolly Pine Stand', $J$. Geophys. Res. 102, 9309-9321.

Katul, G. G., Hsieh, C. I., Kuhn, G., Ellsworth, D., and Nie, D.: 1997b, 'Turbulent Eddy Motion at the Forest-Atmosphere Interface', J. Geophys. Res. 102, 13,409-13,421.

Katul, G. G., Hsieh, C. I., Oren, R., Ellsworth, D., and Phillips, N.: 1996a, 'Latent and Sensible Heat Flux Predictions from a Uniform Pine Forest Using Surface Renewal and Flux Variance Methods', Boundary-Layer Meteorol. 80, 249-282.

Katul, G. G., Albertson, J. D., Hsieh, C. I., Conklin, P. S., Sigmon, J. T., Parlange, M. B., and Knoerr, K. R.: 1996b, 'The Inactive Eddy-Motion and the Large-Scale Turbulent Pressure Fluctuations in the Dynamic Sublayer', J. Atmos. Sci. 53, 2512-2524.

Katul, G. G., Goltz, S. M., Hsieh, C. I., Cheng, Y., Mowry, F., and Sigmon, J.: 1995, 'Estimation of Surface Heat and Momentum Fluxes Using the Flux-Variance Method above Uniform and Non-Uniform Terrain', Boundary-Layer Meteorol. 74, 237-260.

Kondo, J. and Akashi, S.: 1976, 'Numerical Studies on the Two-Dimensional Flow in Horizontally Homogeneous Canopy Layers', Boundary-Layer Meteorol. 10, 255-272.

Leclerc, M. Y., Thurtell, G. W., and Kidd, G. E.: 1988, 'Measurements and Langevin Simulations of Mean Tracer Concentration Fields Downwind from a Circular Source inside an Alfalfa Canopy', Boundary-Layer Meteorol. 43, 287-308.

Leclerc, M. Y., Beissner, K. C., Shaw, R. H., Den Hartog, G., and Neumann, H. H.: 1990, 'The Influence of, Atmospheric Stability on the Budgets of the Reynolds Stress and Turbulent Kinetic Energy within and above a Deciduous Forest', J. Appl. Meteorol. 29, 916-933.

Lenschow, D. H. and Kristensen, L.: 1985, 'Uncorrelated Noise in Turbulence Measurements', J. Atmos. Oceanic Tech. 2, 68-81.

Lenschow, D. H. and Raupach, M. R.: 1991, 'The Attenuation of Fluctuations in Scalar Concentrations through Sampling Tubes', J. Geophys. Res. 96, 15,259-15,268.

Lewellen, W. S., Teske, M. E., and Sheng, Y. P.: 1980, 'Micrometeorological Applications of a Second Order Closure Model of Turbulent Transport', in L. J. S. Bradbury, F. Durst, B. E. Launder, F. W. Schmidt, and J. H. Whitelaw (eds.), Turbulent Shear Flows II, Springer-Verlag, pp. 366-378.

Lu, C. H. and Fitzjarrald, D. R.: 1994, 'Seasonal and Diurnal Variations of Coherent Structures over a Deciduous Forest', Boundary-Layer Meteorol. 69, 43-69.

Moritz, E.: 1989, 'Heat and Momentum Transport in an Oak Forest Canopy', Boundary-Layer Meteorol. 49, 317-329.

Meyers, T. and Paw U, K. T.: 1986, 'Testing of a Higher-Order Closure Model for Modeling Airflow within and above Plant Canopies', Boundary-Layer Meteorol. 37, 297-311.

Paw U, K. T., Brunet, Y., Collineau, S., Shaw, R. H., Maitani, T., Qiu, J., and Hipps, L.: 1992, 'On Coherent Structures in Turbulence above and within Agricultural Plant Canopies', Agric. For. Meteorol. 61, 55-68.

Raupach, M. R., Antonia, R. A., and Rajagopalan, S.: 1991, 'Rough-Wall Turbulent Boundary Layers', Appl. Mech. Rev. 44, 1-25.

Raupach, M. R., Finnigan, J. J., and Brunet, Y.: 1996, 'Coherent Eddies and Turbulence in Vegetation Canopies: The Mixing Layer Analogy', Boundary-Layer Meteorol. 78, 351-382.

Raupach, M. R.: 1988, 'Canopy Transport Processes', in W. L. Steffem and O. T. Denmead (eds.), Flow and Transport in the Natural Environment: Advances and Applications, Springer-Verlag, pp. 95-127.

Raupach, M. R. and Shaw, R. H.: 1982, 'Averaging Procedures for Flow within Vegetation Canopies', Boundary-Layer Meteorol. 22, 79-90.

Raupach, M. R. and Thom, A. S.: 1981, 'Turbulence in and above Canopies', Ann. Rev. Fluid Mech. 13, 97-129. 
Ritter, J. A., Lenschow, D. H., Barrick, J. D., Gregory, G. L., Sache, G. W., Hill, G. F., and Woerner, M. A.: 1990, 'Airborne Flux Measurements and Budget Estimates of Trace Species over the Amazon Basin during the GTE/ABLE 2B Expedition', J. Geophys. Res. 95, 16,875-16,886.

Thompson, N.: 1979, 'Turbulence Measurements above a Pine Forest', Boundary-Layer Meteorol. 16, 293-310.

Thom, A. S.: 1971, 'Momentum Absorption by Vegetation', Quart. J. Roy. Meteorol. Soc. 97, 414428.

Townsend, A. A.: 1976, The Structure of Turbulent Shear Flow, Cambridge University Press, 428 pp.

Wilson, N. R. and Shaw, R. H.: 1977, 'A Higher Order Closure Model for Canopy Flow', J. Appl. Meteorol. 16, 1198-1205.

Wilson, J. D.: 1988, 'A Second Order Closure Model for Flow through Vegetation', Boundary-Layer Meteorol. 42, 371-392.

Wilson, J. D.: 1989, 'Turbulent Transport within the Plant Canopy', in T. A. Black, D. L. Spittlehouse, M. D. Novak, and D. T. Price (eds.), Estimation of Areal Evapotranspiration, IAHS Publication No. 177, pp. 43-80.

Wofsy, S. C., Goulden, M. L., Munger, J. W., Fan, S. M., Bakwin, P. S., Daube, B. C., Bassow, S. L., and Bazzaz, F. A.: 1993, 'Net Exchange of $\mathrm{CO}_{2}$ in a Mid-Latitude Forest', Science 260, 1314-1317.

Yaglom, A. M.: 1979, 'Similarity Laws for Constant-Pressure and Pressure Gradient Turbulent Wall Flows', Ann. Rev. Fluid Mech. 11, 505-540. 